\title{
Analisis Sentimen pada Ulasan Pembelian Produk di Marketplace Shopee Menggunakan Pendekatan Natural Language Processing
}

\author{
Elik Hari Muktafin ${ }^{1}$, Kusrini ${ }^{2}$, Emha Taufiq Luthfi ${ }^{3}$ \\ Magister Teknik Informatika \\ Universitas Amikom Yogyakarta \\ Yogyakarta, Indonesia \\ e-mail: ${ }^{1}$ elik.muktafin@ @students.amikom.ac.id, ${ }^{2}$ kusrini@amikom.ac.id, ${ }^{3}$ emhataufiqluthfi@ amikom.ac.id \\ Diajukan: 1 Juli 2020; Direvisi: 7 Agustus 2020; Diterima: 15 Agustus 2020
}

\begin{abstract}
Abstrak
Ulasan produk di marketplace merupakan informasi yang berharga apabila diolah dengan baik. Penjual dapat melakukan analisis ulasan produk untuk mendapat informasi yang dapat digunakan dalam evaluasi produk dan layanan. Kegiatan analisis ulasan produk tidak cukup dengan melihat jumlah bintang, diperlukan melihat seluruh isi komentar ulasan untuk dapat mengetahui maksud dari ulasan. Apabila dalam jumlah sedikit dapat dilakukan secara manual, namun dalam jumlah banyak lebih efektif menggunakan sistem. Dibutuhkan sistem yang mampu menganalisis banyak ulasan dengan efektif agar memudahkan dalam memahami maksud ulasan. Penelitian ini menggunakan algoritma KNN dan TF-IDF dengan pendekatan NLP untuk mengklasifikasikan ulasan produk "hijab instan" ke dalam 2 kelas (positif dan negatif). Klasifikasi menggunakan pendekatan NLP mendapat akurasi sebesar 76,92\%, presisi 80,00\% dan recall 74,07\%, sedangkan tanpa NLP hanya mendapat akurasi sebesar 69,23\%, presisi 80,00\% dan recall 64,52\%. Kata yang sering muncul pada ulasan dapat menggambarkan penilaian pembeli secara umum pada produk. Pada ulasan positif menunjukkan pembeli puas terhadap kualitas, kecepatan pengiriman dan harga barang, sedangkan pada ulasan negatif pembeli kecewa pada warna, dan jumlah barang yang dikirim tidak sama dengan yang dipesan.
\end{abstract}

Kata kunci: Analisis sentimen, Ulasan produk, Marketplace, KNN, NLP.

\begin{abstract}
Product reviews in the marketplace are valuable information if processed properly. Sellers can analyze product reviews to get information that can be used in evaluating products and services. The activity of analyzing product reviews is not enough to look at the number of stars, it is necessary to see the entire contents of the review comments to be able to find out the meaning of the review. If a small amount is done manually, but in large numbers it is more effective to use the system. A system that is able to analyze reviews effectively is needed to make it easier to understand the intent of reviews. This study uses the KNN and TF-IDF algorithm with the NLP approach to classify "instant hijab" product reviews into 2 classes (positive and negative). Classification using the NLP approach gets $76.92 \%$ accuracy, 80,00\% precision and $74,07 \%$ recall, while without NLP it only gets $69.23 \%$ accuracy, $80,00 \%$ precision and $64,52 \%$ recall. Words that often appear on reviews can describe the general buyer's judgment on the product. The positive reviews show the buyer is satisfied with the quality, speed of delivery and the price of the goods, while the negative reviews the buyer is disappointed in the color, and the number of items sent is not the same as ordered.
\end{abstract}

Keywords: Sentiment analysis, Product reviews, Marketplace, KNN, NLP.

\section{Pendahuluan}

Marketplace merupakan perkembangan dari e-commerce sebagai media daring berbasis internet untuk tempat melakukan kegiatan bisnis dan transaksi antara pembeli dan penjual [1]. Pada marketplace pembeli dapat mencari barang yang ingin di beli dari banyak penjual atau toko. Berdasarkan data Peta E-Commerce Indonesia yang dikeluarkan oleh iPrice, Shopee adalah marketplace dengan jumlah pengunjung terbanyak di Indonesia pada kuartal pertama tahun 2020 dengan jumlah pengunjung per bulan 
mencapai 71 juta pengunjung [2]. Kondisi ini dimanfaatkan oleh produsen, Industri Kecil Menengah (IKM), Usaha Mikro Kecil Menegah (UMKM), pemasok, maupun distributor untuk menjangkau calon pembeli yang membutuhkan produknya. Salah satu produk yang banyak dijual di Shopee adalah produk busana muslim. Kualitas produk busana muslim selain dapat dilihat dari foto dan deskripsi produk yang tertera, dapat pula dilihat dari ulasan produk dari pembeli sebelumnya. Ulasan produk merupakan salah satu sumber informasi tentang kualitas produk dan sangat berpengaruh pada konsumen [3].

Dalam kegiatan pembelian barang di marketplace, pembeli dapat memberikan ulasan setelah menerima barang yang dibeli. Ulasan pembelian produk terdiri dari bintang dan isi komentar ulasan yang berisi tanggapan, apresiasi maupun kritik dan masukan pada produk yang telah dibeli tersebut [4]. Semakin banyak jumlah bintang yang dimiliki, maka semakin baik pula reputasi yang dimiliki produk tersebut [5]. Ulasan pembelian produk memiliki pengaruh yang signifikan terhadap minat beli dari pembeli lain [6]. Ulasan pembelian produk dapat digunakan oleh penjual untuk mendapat informasi untuk bahan perbaikan pada produk dan layanan sehingga tercipta kepuasan pelanggan. Kepuasan pelanggan merupakan hal penting yang menjadi tujuan perusahaan [7].

Analisis ulasan secara mudah dapat dilakukan dengan melihat jumlah bintang yang diberikan oleh pembeli, tetapi jumlah bintang tidak dapat mewakili isi dari keseluruhan ulasan. Diperlukan melihat seluruh isi komentar ulasan untuk dapat mengetahui keseluruhan maksud ulasan. Sangat dimungkinkan untuk menganalisis ulasan secara manual dengan melihat satu persatu, namun apabila ulasan yang dimiliki banyak akan lebih cepat menggunakan sistem analisis sentimen [8].

Pada penelitian ini peneliti melakukan analisis sentimen pada ulasan produk di marketplace Shopee. Bagian ulasan produk terdiri dari isi komentar dengan format teks bebas dan peringkat jumlah bintang dari 1 sampai 5 [9]. Isi komentar ulasan digunakan untuk mengetahui informasi yang menjadi fokus pembeli dalam memberikan ulasan. Isi komentar ulasan dapat berisi lebih dari satu penilaian atribut produk, sedangkan setiap ulasan hanya memiliki satu penilaian jumlah bintang, sehingga jumlah bintang tidak dapat mewakili setiap fitur produk yang dinilai oleh pembeli [9]. Informasi yang disampaikan pembeli dapat merujuk pada fitur produk seperti harga, kualitas, bahan, warna, bentuk, ukuran, rasa, jumlah, maupun pada pelayanan yang diberikan seperti pengemasan, lama pengiriman, dan tanggapan penjual.

Beberapa penelitian sebelumnya mengatakan bahwa ulasan produk memiliki pengaruh positif pada niat pembelian, sering kali calon pembeli mempertimbangkan faktor ulasan untuk meyakinkan kualitas produk yang akan dibeli [10]. Penelitian tentang sentimen analisis pada ulasan produk sudah pernah dilakukan oleh peneliti sebelumnya. Penelitian oleh Lutfi dan Permatasari [11] menganalisis ulasan produk di marketplace Bukalapak untuk mengetahui sentimen ulasan pengguna bernilai positif atau negatif dengan pendekatan memanfaatkan Support Vector Machine dengan akurasi 93,42\%. Pada penelitian yang dilakukan Muljono dan Dian [12], mempresentasikan analisis sentimen terhadap data opini di Twitter pada pelayanan situs marketplace di Indonesia menggunakan algoritma Naive Bayes dengan hasil akurasi sebesar 93.33\%. Pada penelitian lain oleh Norman Kendal [13] menunjukkan penggunaan Natural Language Processing (NLP) dapat diterapkan secara efektif ke pasar produk busana secara daring untuk memprediksi kategori atau sub kategori produk dari judul produk.

Tujuan dari penelitian ini adalah menganalisis sentimen ulasan pembelian produk pada produk "hijab instan" di Shopee menggunakan algoritma KNN dengan pembobotan TF-IDF dan diklasifikasi ke dalam 2 kelas (positif dan negatif). Kemudian dibandingkan tingkat keberhasilan klasifikasi antara data yang melalui pra-pemrosesan dengan dan tanpa pendekatan NLP. Tujuan lain dari penelitian ini adalah untuk mengetahui fitur apa yang menjadi fokus ulasan positif dan negatif pada produk hijab instan, sehingga penjual dapat melakukan perbaikan dan peningkatan kualitas produk dan layanan secara tepat. Permasalahan dalam menganalisis ulasan pembelian produk di marketplace adalah banyaknya penggunaan singkatan dan bahasa yang tidak baku sehingga sulit dimengerti oleh sistem. Oleh karena itu, pendekatan Natural Language Processing (NLP) diperlukan untuk memperbaiki bahasa pada isi komentar ulasan sehingga mencapai kinerja maksimal dalam analisis sentimen [14]. Tanpa NLP, Machine Learning tidak dapat membuat kemajuan yang berarti [15].

\section{Metode Penelitian}

Alur penelitian dalam analisis sentimen ulasan pembelian produk di Shopee menggunakan pendekatan Natural Language Processing (NLP) terdiri dari beberapa tahapan seperti yang ditunjukkan pada Gambar 1. Tahapan awal penelitian ini dimulai dengan penentuan produk yang akan dianalisis, lalu dilanjutkan dengan pengumpulan data ulasan produk. Dilakukan pra-pemrosesan pada ulasan yang sudah terkumpul dengan dan tanpa pendekatan NLP sehingga menghasilkan 2 dataset, dengan pendekatan NLP dan dataset tanpa pendekatan NLP. Setiap dataset dibagi menjadi data latih dan data uji, kemudian 
diterapkan perhitungan pembobotan $T F-I D F$ pada kedua dataset untuk dibandingkan hasil keduanya dan dilakukan analisis hasil.

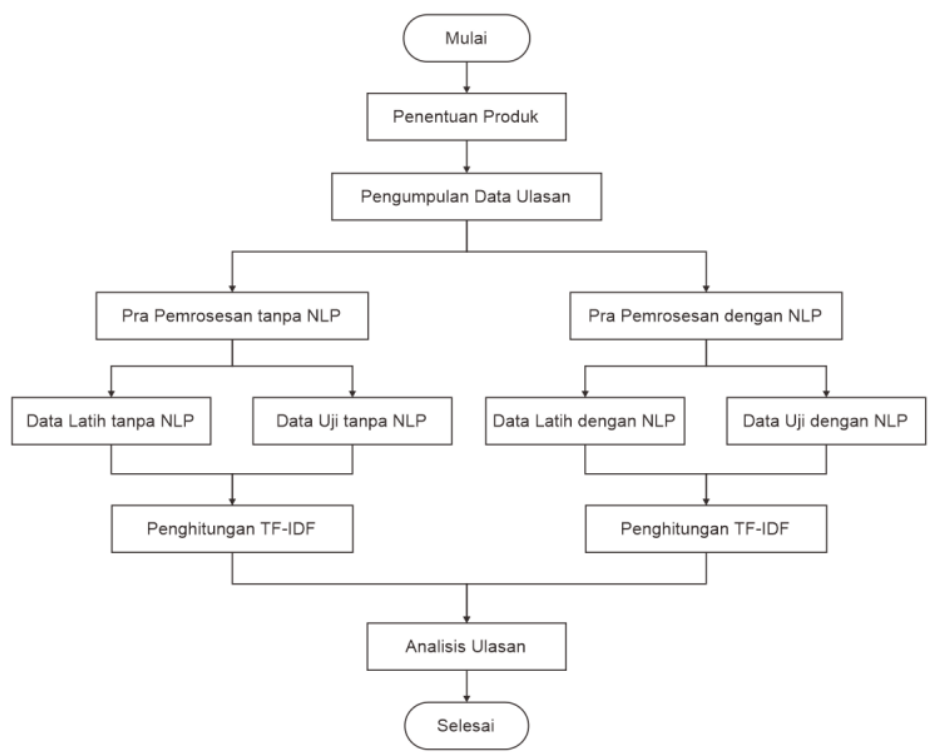

Gambar 1. Alur penelitian

Pada tahapan penentuan produk, produk yang digunakan dalam penelitian ini adalah 120 produk terlaris di Shopee berdasarkan hasil pencarian produk dengan kata kunci "hijab instan". Produk dipilih berdasarkan urutan jumlah penjualan produk tanpa melihat asal toko dan asal wilayah. Alasan pemilihan kata kunci "hijab instan" yaitu: 1) Memiliki jumlah pencarian lebih tinggi dibanding tipe hijab lainnya menurut Google Trends per April 2020 [16]; 2) Memiliki penjualan yang tinggi di Shopee dengan penjualan tertinggi mencapai 48 ribu produk per bulan dari satu produk [17]; 3) Tipe hijab instan memiliki fitur yang kompleks mulai dari model, bahan, warna, ukuran, potongan, dan jahitan.

Tahapan pengumpulan data ulasan dilakukan dengan menggunakan aplikasi Scraper yang dibuat secara mandiri menggunakan bahasa Python. Setiap produk diambil 6 ulasan dari halaman pertama pada ulasan bintang 1 sampai ulasan bintang 5, sehingga menghasilkan total 3.341 ulasan.

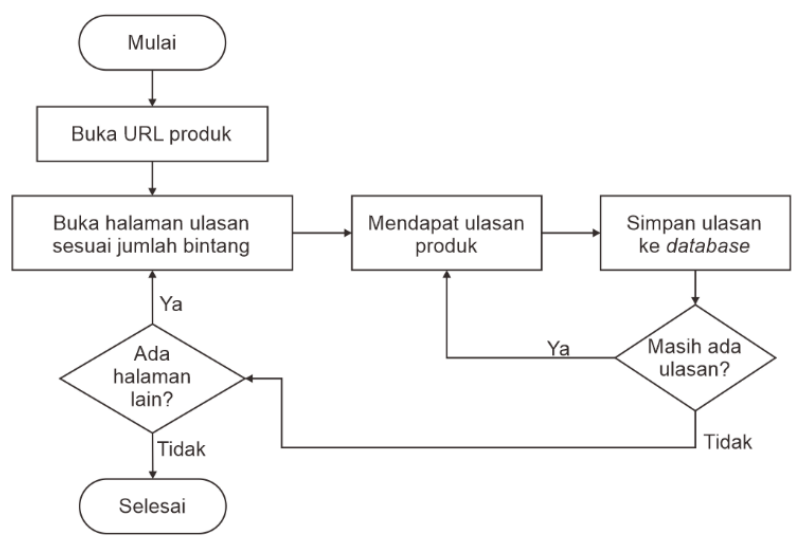

Gambar 2. Proses pengambilan komentar menggunakan aplikasi Scraper.

Alur kerja sistem aplikasi Scraper ditunjukkan pada Gambar 2. Proses dimulai dengan mengakses $U R L$ produk dan membuka halaman ulasan dengan jumlah bintang 1 , kemudian mengunduh satu persatu ulasan produk yang muncul dan disimpan ke basis data. Apabila semua ulasan dengan jumlah bintang 1 telah diunduh, aplikasi Scraper akan membuka halaman ulasan dengan jumlah bintang 2 dan seterusnya hingga mencapai halaman ulasan dengan jumlah bintang 5 . 
Ulasan pembelian produk disimpan dalam basis data MySQL agar mudah dikelola [18]. Dari 3.341 ulasan yang didapat, dipilih ulasan dengan kriteria berikut:

1. Setiap produk diambil maksimal 1 ulasan pada setiap jumlah bintang yang memenuhi kriteria dan diurutkan berdasarkan ulasan terbaru.

2. Ulasan dengan panjang kurang dari 100 karakter tidak digunakan.

3. Ulasan yang digunakan hanyalah ulasan yang memiliki tag.

4. Ulasan yang hanya berisi emoticons atau simbol tidak digunakan.

5. Ulasan yang hanya berisi satu kata yang sama tidak digunakan, contohnya "mantul mantul mantul mantul mantul mantul mantul mantul mantul".

6. Ulasan yang tidak terdapat dalam kosa kata bahasa Indonesia tidak digunakan, contohnya "urkbroekheueofnfbsheowmshsodbaegaefeafafafafafaadadada"

Seleksi ulasan menghasilkan 260 ulasan yang layak sebagai dataset. Dataset dilabeli secara manual oleh 5 koresponden, terdiri dari 3 koresponden dari pembeli atau pengguna Shopee yang memiliki pengalaman dalam membeli produk di Shopee dan 2 koresponden adalah penjual di Shopee. Dataset diberi label dalam 2 kelas, ulasan positif dan negatif untuk setiap produk.

Dataset kemudian melalui proses pra-pemrosesan untuk membersihkan dan menyiapkan data sehingga siap dianalisis [19]. Pra-pemrosesan dilakukan dalam 2 keadaan, yang pertama pra-pemrosesan tanpa pendekatan NLP yang terdiri dari tahapan menghilangkan emoticons dan simbol, lowercase folding, dan penanganan tag. Yang kedua pra-pemrosesan dengan pendekatan Natural Language Processing (NLP) dengan tujuan untuk memperbaiki bahasa yang ada pada ulasan, karena pada ulasan ditemukan banyak penggunaan kata yang tidak baku dan singkatan. Natural Language Processing (NLP) merupakan salah satu cabang ilmu Kecerdasan Buatan yang berfokus pada pengolahan bahasa natural yang dapat digunakan untuk mengatasi hambatan pengenalan bahasa percakapan sehari hari oleh sistem komputer.

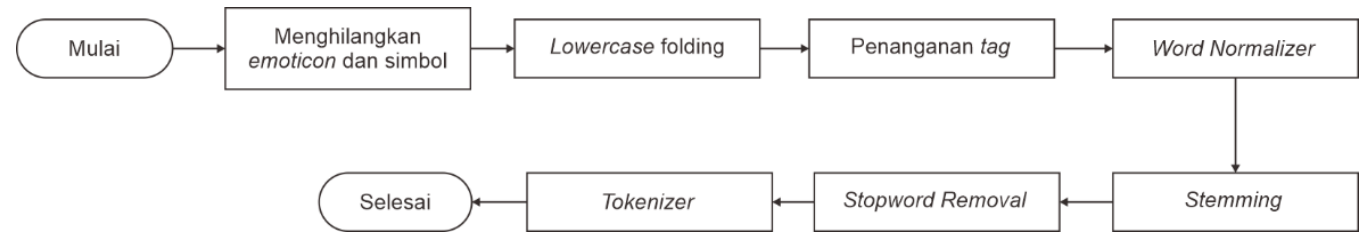

Gambar 3. Tahap pra-pemrosesan menggunakan pendekatan NLP.

Alur kerja tahapan pra-pemrosesan dengan pendekatan NLP ditunjukkan pada Gambar 3, dengan penjelasan setiap tahapannya sebagai berikut:

a. Menghilangkan emoticons dan simbol

Pada penelitian ini emoticons dan simbol yang ada pada ulasan dibuang karena penelitian ini hanya berfokus pada teks yang terkandung dalam ulasan. Simbol yang dibuang adalah “ ”, “ ’”, “!”, “\$”,

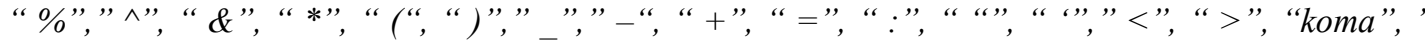
titik”, “?”, “/”, “\”, “\#”, dan “|”. Ulasan yang mengandung simbol seperti “memuaskan banget kak : )" setelah diproses maka menjadi "memuaskan banget kak”.

b. Lowercase folding

Lowercase folding adalah mengubah semua huruf menjadi huruf kecil agar terhitung sebagai kata yang sama [20]. Komentar " Bagus banget sesuai pesanan” menjadi "bagus banget sesuai pesanan”, huruf " $B$ " kapital diubah menjadi " $b$ " huruf kecil.

c. Penanganan tag

Tag ulasan adalah potongan informasi yang telah disediakan Shopee dan dapat disertakan pada ulasan pembelian produk. Tidak semua ulasan mengandung tag, sehingga perlu dilakukan penanganan khusus pada ulasan yang mempunyai tag. Tag pada ulasan ditambahkan menjadi bagian dari isi komentar ulasan. Contoh tag yang disediakan Shopee seperti "Kecepatan pengiriman sangat baik”, "Respon penjual sangat baik".

d. Word Normalizer

Word Normalizer digunakan untuk memperbaiki kata-kata dalam ulasan sehingga menghasilkan kalimat yang baik dan benar sesuai dengan aturan tata bahasa Indonesia. Peningkatan ini diperlukan untuk memudahkan pembaca memahami makna kalimat [1]. Komentar "barangnya bagus bgt" maka setelah proses Word Normalizer menjadi "barangnya bagus banget". Kata "bgt" diubah menjadi "banget" sehingga lebih mudah dipahami. 
e. Stemming

Stemming berfungsi untuk membuat suatu kata menjadi kata dasar, dengan menghilangkan semua imbuhan yang ada pada kata tersebut [21]. Sebagai contoh kalimat "bahannya halus dan tidak membuat kegerahan" kemudian diubah menjadi "bahan halus dan tidak buat gerah"

f. Stopword Removal

Stopword removal berfungsi untuk menghilangkan kata-kata yang mempunyai jumlah kemunculan banyak tapi tidak terlalu penting [22]. Kata yang masuk stopword seperti "yang", "dan", "di", "dari" sehingga menyisakan kata-kata yang penting. Sebagai contoh kalimat "barang yang warna hijau dan biru bagus" kemudian diubah menjadi "barang warna hijau biru bagus".

g. Tokenizer

Tokenizer berfungsi untuk membagi teks input menjadi array token, karakter yang digunakan dalam bahasa Indonesia adalah alfabet dan setiap token dipisahkan oleh spasi. Sebagai contoh kalimat "barangnya bagus banget" kemudian diubah menjadi "barangnya", "bagus", "banget".

Dataset yang telah melalui tahapan pra-pemrosesan dengan dan tanpa pendekatan NLP, dibagi menjadi 2 bagian dengan komposisi 208 data latih dan 52 data uji. Kemudian diterapkan pembobotan dengan algoritma Term Frequency Inverse Document Frequency (TF-IDF). TF-IDF digunakan untuk memberikan pembobotan hubungan suatu kata atau istilah terhadap keseluruhan ulasan. Frekuensi kemunculan kata di dalam ulasan menunjukkan seberapa penting kata itu di dalam ulasan tersebut, dan ulasan mana yang memiliki kata tersebut sehingga ulasan dapat diklasifikasikan ke dalam 2 kelas (ulasan positif dan ulasan negatif) [23]. Perhitungan TF-IDF menggunakan Persamaan 1.

$$
W_{x, y}=t f_{x, y} \times \log \left(\frac{N}{d f_{x}}\right)
$$

Di mana $W_{x, y}$ adalah bobot istilah $\left(t_{y}\right)$ terhadap dokumen $\left(d_{x}\right)$. Sedangkan $t f_{x, y}$ adalah jumlah kemunculan istilah $\left(t_{y}\right)$ dalam dokumen $\left(d_{x}\right) . N$ adalah jumlah semua dokumen yang ada dalam dataset dan $d f_{x}$ adalah jumlah dokumen yang mengandung istilah $\left(t_{y}\right)$, minimal ada satu kata yaitu istilah $\left(t_{y}\right)$.

\section{Hasil dan Pembahasan}

\subsection{Daftar Ulasan Produk Shopee}

Ulasan yang digunakan didapatkan dari kegiatan pencarian ulasan produk pada bulan April 2020 di Shopee. Ulasan diambil dari produk terlaris dengan pencarian menggunakan kata kunci "hijab instan". Contoh ulasan yang digunakan ditunjukkan pada Tabel 1.

Tabel 1. Contoh ulasan produk.

\begin{tabular}{|c|c|c|c|c|c|}
\hline No & Akun & Isi Ulasan & Tag Ulasan & Bintang & Label \\
\hline 1 & $\mathrm{w}^{* * * * * * \mathrm{c}}$ & $\begin{array}{l}\text { Alhamdulillah owner nya baik, yaa walaupun aku chatt } \\
\text { agak lama balasnya saya juga maklumin karena yang beli } \\
\text { juga bukan aku aja toh. InAku order } 100 \text { piece yang } \\
\text { datang cuma } 97 \text { dan Alhamdulillah nya begitu } \\
\text { mengajukan pengembalian dana langsung diBALIKIN }\end{array}$ & $\begin{array}{l}\text { Kualitas produk sangat } \\
\text { baik. }\end{array}$ & $5 / 5$ & Positif \\
\hline 2 & nasrul8623 & $\begin{array}{l}\text { Ukuran nya kok tidak sama ya. Ada yang kecil ada yang } \\
\text { pas. Hmm gpp deh tak kasih bintang } 4 \text { aja ya soallnya } \\
\text { masih belum konsisten dengan produknya. }\end{array}$ & Kualitas produk baik. & $4 / 5$ & Negatif \\
\hline 3 & $\mathrm{~d} * * * * * \mathrm{e}$ & $\begin{array}{l}\text { Tipis banget ternyata huhuuu sedih tapi ya lumayan aja } \\
\text { lah buat dirumah sehari } 2 \text { mah harus pake ciput yg nutup } \\
\text { klo gak nerawang gitu mungkin karna harganya } \\
\text { juga..InTapi emg pengirimannya termasuk cepet sih } \\
\text { ini..Inya plus minus gitu gaes..InHappy shopping gaes.. }\end{array}$ & $\begin{array}{ll}\text { Kualitas } & \text { produk } \\
\text { standar. Harga } & \text { produk } \\
\text { standar. } & \end{array}$ & $3 / 5$ & Negatif \\
\hline 4 & $\mathrm{n} * * * * * \mathrm{r}$ & $\begin{array}{l}\text { untuk warna mocca, hitam, maroon udh bener dkirim } \\
\text { bergo meskipun jahitannya ga rapi samsek. tapi yg navy } \\
\text { kenapa yg dikirim bkn bergo malah kerudung segitiga } \\
\text { sih. ini beli barengan sm temen2. pada nyalahin yg beli } \\
\text { navy karna yg dtg bukan bergo }\end{array}$ & $\begin{array}{l}\text { Kualitas produk kurang } \\
\text { baik. }\end{array}$ & $2 / 5$ & Negatif \\
\hline 5 & aiiunii05 & $\begin{array}{l}\text { Belanja ke dua dan alhamdulillah puas lagi, pertahankan } \\
\text { kualitas nya ya semoga berkah toko nya dan laku, aamiin } \\
\text { suka banget sama kerudung nya dan bahan nya nyaman, } \\
\text { secara nyari di pasaran udah banyak yg jual tapi bahan } \\
\text { nya jersey kebanyakan dan kurang suka jersey, kalo ini } \\
\text { diamon jadi enak pake nya }\end{array}$ & $\begin{array}{l}\text { Kualitas produk sangat } \\
\text { baik. Produk original. } \\
\text { Harga produk sangat } \\
\text { baik. Kecepatan } \\
\text { pengiriman sangat baik. }\end{array}$ & $5 / 5$ & Positif \\
\hline
\end{tabular}


Pada Tabel 1, akun $w^{* * * * *} c$ menuliskan ulasan tentang layanan perpesanan dan jumlah barang yang dikirim tidak sesuai, tetapi memberikan tag ulasan kualitas produk sangat baik dengan jumlah bintang $5 / 5$ dan diberikan label positif. Akun nasrul8623 menuliskan ulasan tentang ukuran yang tidak sesuai dan memberi tag kualitas produk baik dengan jumlah bintang 4/5 dan diberikan label negatif. Bisa disimpulkan bahwa jumlah bintang pada ulasan tidak selalu mewakili isi ulasan. Ulasan dengan jumlah bintang $5 / 5$ tidak menjamin pembeli puas pada semua fitur barang dan pelayanan yang didapat. Fitur tag pada ulasan membantu pembeli untuk lebih spesifik menyebut fitur apa saja yang diulas. Informasi dari ulasan ini dapat diolah untuk menjadi perbaikan oleh penjual ke depan.

\subsection{Analisis Ulasan}

Ulasan yang digunakan sebanyak 260 ulasan, yang telah diberi label oleh 5 koresponden dan menghasilkan 129 ulasan positif dan 131 ulasan negatif. Ulasan dijadikan dataset dengan komposisi 208 data latih dan 52 data uji, kemudian dilakukan pra-pemrosesan dengan pendekatan NLP. Pada tahap prapemrosesan diterapkan fitur word normalizer, stemming, dan stopword removal untuk setiap ulasan.

Word normalizer untuk menangani variasi penulisan kata yang memiliki makna yang sama agar terhitung sebagai istilah tunggal [24]. Contoh variasi penulisan kata yang memiliki makna sama ditunjukkan pada Tabel 2.

Tabel 2. Variasi penulisan kata pada ulasan yang memiliki makna sama.

\begin{tabular}{cccc}
\hline No & Istilah pada ulasan & Word normalizer & Jumlah ulasan \\
\hline 1 & tidak & tidak & 40 \\
\hline 2 & tdk & tidak & 11 \\
\hline 3 & gak & tidak & 33 \\
\hline 4 & $\mathrm{~g}$ & tidak & 7 \\
\hline 5 & tdak & tidak & 1 \\
\hline 6 & ga & tidak & 40 \\
\hline 7 & gk & tidak & 10 \\
\hline 8 & banget & banget & 28 \\
\hline 9 & bgt & banget & 12 \\
\hline 10 & bget & banget & 1 \\
\hline
\end{tabular}

Pada Tabel 2 menunjukkan variasi kata yang memiliki makna sama. Kata " $g a$ " ditemukan pada 40 ulasan dan kata "gak" ditemukan pada 33 ulasan, digunakan oleh pembeli untuk menggantikan kata "tidak". Kata "bgt" ditemukan pada 12 ulasan dan kata "bget" ditemukan pada 1 ulasan yang digunakan oleh pembeli untuk menggantikan kata "banget". Penggunaan word normalizer dapat menangani banyaknya variasi kata yang digunakan pada penulisan ulasan oleh pembeli untuk diubah menjadi istilah yang sama.

Selanjutnya dilakukan proses stemming pada dataset, untuk menghilangkan awalan, sisipan dan akhiran kata sehingga menjadi bentuk dasarnya, dengan tujuan pengambilan informasi menjadi efisien dan efektif [25]. Contoh penerapan stemming ditunjukkan pada Tabel 3.

Tabel 3. Hasil penerapan stemming.

\begin{tabular}{cccc}
\hline No & Istilah pada ulasan & Stemming & Jumlah ulasan \\
\hline 1 & dikirim & kirim & 24 \\
\hline 2 & dikirimkan & kirim & 1 \\
\hline 3 & langganan & langgan & 26 \\
\hline 4 & berlangganan & langgan & 1 \\
\hline 5 & jahitannya & jahit & 10 \\
\hline 6 & dijahit & jahit & 2 \\
\hline 7 & penjahit & jahit & 1 \\
\hline 8 & pesanan & pesan & 23 \\
\hline 9 & memesan & pesan & 1 \\
\hline 10 & dipesan & pesan & 1 \\
\hline
\end{tabular}

Pada Tabel 3 dapat dilihat kata-kata pada ulasan seperti "dikirim" dan "dikirimkan" apabila dihilangkan awalan, sisipan dan akhiran akan menjadi kata dasar "kirim". Begitu juga dengan kata "jahitannya", "dijahit", dan "penjahit" setalah melalui proses stemming menjadi kata dasar "jahit". Stemming membuat kata-kata pada ulasan menjadi bentuk dasarnya dan menjadi istilah yang sama.

Selanjutnya dilakukan proses stopword removal untuk menghilangkan stopword dari ulasan. Daftar stopword yang digunakan dibuat sendiri mengacu pada konteks kata yang sering dipakai dalam 
ulasan maupun dalam jual beli secara daring. Contoh daftar stopword yang dipakai ditunjukkan pada Tabel 4.

Tabel 4. Contoh daftar stopword.

\begin{tabular}{ccc}
\hline No & Stopword & Jumlah kemunculan \\
\hline 1 & yang & 214 \\
\hline 2 & di & 104 \\
\hline 3 & tapi & 92 \\
\hline 4 & dan & 73 \\
\hline 5 & ya & 62 \\
\hline 6 & juga & 61 \\
\hline 7 & jadi & 34 \\
\hline 8 & untuk & 32 \\
\hline 9 & dengan & 31 \\
\hline 10 & ke & 22 \\
\hline
\end{tabular}

Dapat dilihat pada Tabel 4, kata "yang" merupakan salah satu daftar stopword yang paling banyak muncul, yaitu sebanyak 214 kali, dan kata " $d i$ " yang muncul sebanyak 104 kali. Selain dalam bentuk kata angka juga masuk ke dalam stopword, angka tidak berpengaruh pada analisis sentimen dan dapat dihapus, sehingga dapat mengurangi kebisingan dan meningkatkan efisiensi [26]. Hasil keseluruhan proses prapemrosesan dapat dilihat pada Tabel 5.

Tabel 5. Hasil pra-pemrosesan.

\begin{tabular}{|c|c|c|c|c|c|}
\hline \multirow{2}{*}{ No } & \multirow{2}{*}{ Ulasan Produk } & \multicolumn{3}{|c|}{ Pra-pemrosesan } & \multirow{2}{*}{$\begin{array}{l}\text { Label } \\
\text { Aktual }\end{array}$} \\
\hline & & Word Normalizer & Stemming & Stopword Removal & \\
\hline 1 & $\begin{array}{l}\text { Mksh admin, jilbabny } \\
\text { sudah datang, bagus } \\
\text { walaupun agak tipis dan } \\
\text { sedikit menerawang, tapi } \\
\text { kalau dipake smg gak } \\
\text { nerawang. }\end{array}$ & $\begin{array}{l}\text { terimakasih admin } \\
\text { jilbabnya sudah datang } \\
\text { bagus walaupun agak tipis } \\
\text { dan sedikit menerawang } \\
\text { tapi kalau dipakai semoga } \\
\text { tidak menerawang }\end{array}$ & $\begin{array}{l}\text { terimakasih admin jilbab } \\
\text { sudah datang bagus } \\
\text { walaupun agak tipis dan } \\
\text { sedikit terawang tapi } \\
\text { kalau pakai moga tidak } \\
\text { terawang }\end{array}$ & $\begin{array}{lr}\text { terimakasih admin } \\
\text { jilbab } & \text { datang } \\
\text { bagus } & \text { tipis } \\
\text { terawang } & \text { dipakai } \\
\text { terawang } & \end{array}$ & Positif \\
\hline 2 & $\begin{array}{l}\text { Kualitas produk sangat } \\
\text { bagus, produk original, } \\
\text { kecepatan produk sangat } \\
\text { baik, semoga kedepannya } \\
\text { makin baik dan amanah ya } \\
\text { semoga berkah amiiinnnn }\end{array}$ & $\begin{array}{l}\text { kualitas produk sangat } \\
\text { bagus produk original } \\
\text { kecepatan produk sangat } \\
\text { baik semoga kedepannya } \\
\text { makin baik dan amanah ya } \\
\text { semoga berkah amin }\end{array}$ & $\begin{array}{l}\text { kualitas produk sangat } \\
\text { bagus produk original } \\
\text { cepat produk sangat baik } \\
\text { moga depan makin baik } \\
\text { dan amanah ya moga } \\
\text { berkah amin }\end{array}$ & $\begin{array}{l}\text { kualitas } \quad \text { produk } \\
\text { bagus } \\
\text { original produk } \\
\text { produk baik baik } \\
\text { amanah berkah }\end{array}$ & Positif \\
\hline 3 & $\begin{array}{l}\text { Bagus nih, bregonya depan } \\
\text { belakang panjang. Paling } \\
\text { sebel, brego biasanya } \\
\text { pendek diblakang, yg ini } \\
\text { suka bgt. Talinya tebal. } \\
\text { Jahitannya bagus cuma msh } \\
\text { harus potongin sisa2 } \\
\text { benang aja. }\end{array}$ & $\begin{array}{l}\text { bagus ini bregonya depan } \\
\text { belakang panjang paling } \\
\text { sebel brego biasanya } \\
\text { pendek di belakang yang ini } \\
\text { suka banget talinya tebal } \\
\text { jahitannya bagus cuma } \\
\text { masih harus memotong sisa } \\
\text { benang saja }\end{array}$ & $\begin{array}{l}\text { bagus ini brego depan } \\
\text { belakang panjang paling } \\
\text { sebel brego biasa pendek } \\
\text { di belakang yang ini suka } \\
\text { banget tali tebal jahit } \\
\text { bagus cuma masih harus } \\
\text { potong sisa benang saja }\end{array}$ & $\begin{array}{l}\text { bagus brego sebel } \\
\text { brego suka tali } \\
\text { tebal jahit bagus } \\
\text { potong sisa benang }\end{array}$ & Positif \\
\hline 4 & $\begin{array}{l}\text { Ukurannya kok engak sama } \\
\text { ya. Ada yang kecil ada yang } \\
\text { pas. Hmm gpp deh tak kasih } \\
\text { bintang } 4 \text { aja ya soalnya } \\
\text { masih belum konsisten } \\
\text { dengan produknya. }\end{array}$ & $\begin{array}{l}\text { ukurannya kok tidak sama } \\
\text { ya ada yang kecil ada yang } \\
\text { sesuai tidak apa apa deh } \\
\text { tidak kasih bintang saja ya } \\
\text { soalnya masih belum } \\
\text { konsisten } \\
\text { produknya }\end{array}$ & $\begin{array}{l}\text { ukur kok tidak sama ya } \\
\text { ada yang kecil ada yang } \\
\text { sesuai tidak apa apa deh } \\
\text { tidak kasih bintang saja } \\
\text { ya soal masih belum } \\
\text { konsisten dengan produk }\end{array}$ & $\begin{array}{l}\text { ukur kecil sesuai } \\
\text { kasih bintang soal } \\
\text { belum konsisten } \\
\text { produk }\end{array}$ & Negatif \\
\hline 5 & $\begin{array}{l}\text { Tipis banget ternyata huhu } \\
\text { sedih tapi ya lumayan aja } \\
\text { lah buat dirumah sehari } 2 \\
\text { mah harus pake ciput yg } \\
\text { nutup klo gak nerawang } \\
\text { gitu mungkin karna } \\
\text { harganya. }\end{array}$ & $\begin{array}{l}\text { tipis banget ternyata huhu } \\
\text { sedih tapi ya lumayan saja } \\
\text { lah buat dirumah sehari } \\
\text { mah harus pakai ciput yang } \\
\text { menutup kalau tidak } \\
\text { nerawang begitu mungkin } \\
\text { karena harganya }\end{array}$ & $\begin{array}{l}\text { tipis banget nyata huhu } \\
\text { sedih tapi ya lumayan } \\
\text { saja lah buat rumah hari } \\
\text { mah harus pakai ciput } \\
\text { yang tutup kalau tidak } \\
\text { nerawang begitu } \\
\text { mungkin karena harga }\end{array}$ & $\begin{array}{l}\text { tipis nyata sedih } \\
\text { lumayan rumah } \\
\text { hari pakai ciput } \\
\text { tutup nerawang } \\
\text { harga }\end{array}$ & Negatif \\
\hline
\end{tabular}

Pada Tabel 5 menunjukkan ulasan produk yang telah melewati pra-pemrosesan menggunakan pendekatan NLP dengan fitur word normalize, stemming, dan stopword removal. Salah satu indikator kepuasan pelanggan adalah pencapaian performa dari sebuah produk yang diterima oleh pelanggan sama dengan ekspektasi pelanggan itu sendiri [27]. Dilakukan pelanggan dengan memberikan ulasan menggunakan kata berkonotasi positif, hal ini sesuai dengan hasil ulasan yang diberi label oleh koresponden 
di mana ulasan terdapat kata "bagus", "suka" dan "cepat". Sedangkan indikator pelanggan tidak puas adalah dengan memberikan ulasan dengan kata berkonotasi negatif, seperti kata "tidak", "kecewa", dan "tipis".

Dalam ulasan nomor 1, walaupun berlabel positif tetapi pada isi ulasan terdapat kritikan untuk penjual yang menggambarkan bahan hijab dengan kata "tipis". Dari contoh ini dapat membuktikan bahwa pemberian jumlah bintang tinggi tidak selalu menggambarkan apa yang dirasakan oleh pembeli. Terkadang ada pembeli yang kecewa pada satu fitur tapi puas pada fitur lainnya, ada pula pembeli yang kecewa tetapi memberikan kesempatan perbaikan pada penjual dengan tetap memberi jumlah bintang tinggi.

\subsection{Perhitungan KNN Menggunakan TF-IDF}

Penelitian ini menggunakan algoritma KNN dengan $k=3$ untuk melakukan klasifikasi ulasan. Penggunaan KNN didukung TF-IDF untuk mengukur bobot atau tingkat pentingnya sebuah kata dalam ulasan [28]. Perhitungan TF-IDF dilakukan pada 208 data latih dan 52 data uji dalam keadaan data sesudah melalui pra-pemrosesan dengan dan tanpa pendekatan NLP. Kemudian dihitung jumlah kecocokan hasil pelabelan dari prediksi 52 data uji dibandingkan dengan pelabelan manual oleh koresponden menggunakan confusion matrix. Confusion matrix membagi keadaan menjadi; True Positif (TP) menunjukkan jumlah data dengan kelas positif dan hasil prediksi benar, True Negatif (TN) menunjukkan jumlah data dengan kelas negatif dan hasil prediksi benar, False Positif (FP) menunjukkan jumlah data dengan kelas positif dan hasil prediksi salah dan False Negatif (FN) menunjukkan jumlah data dengan kelas negatif dan hasil prediksi salah. Hasil prediksi ditunjukkan pada Tabel 6.

Tabel 6. Hasil confusion matrix data uji dengan dan tanpa pra-pemrosesan NLP.

\begin{tabular}{ccc}
\hline Hasi Klasifikasi & Tanpa Pra-pemrosesan & Dengan Pra-pemrosesan \\
\hline True Positif (TP) & 20 & 20 \\
\hline True Negatif (TN) & 16 & 20 \\
\hline False Positif (FP) & 5 & 5 \\
\hline False Negatif (FN) & 11 & 7 \\
\hline
\end{tabular}

Hasil dari confusion matrix kemudian dilakukan perhitungan untuk mendapatkan nilai akurasi, presisi dan recall. Akurasi adalah rasio antara sampel yang diklasifikasikan dengan benar dibandingkan dengan jumlah total sampel, akurasi dihitung menggunakan Persamaan 2. Presisi adalah proporsi sampel positif yang diklasifikasikan dengan benar terhadap jumlah total sampel yang di prediksi positif, presisi dihitung menggunakan Persamaan 3. Recall adalah sampel positif yang diklasifikasikan dengan benar ke total jumlah sampel positif, recall dihitung menggunakan Persamaan 4 [29].

$$
\begin{gathered}
\text { Akurasi }=\frac{T P+T N}{T P+F P+F N+T N} \\
\text { Presisi }=\frac{T P}{F P+T P} \\
\text { Recall }=\frac{T P}{T P+F N}
\end{gathered}
$$

Persamaan 2, 3 dan 4 diterapkan pada hasil pengujian dua keadaan data uji, yaitu tanpa pendekatan NLP dan dengan pendekatan NLP, didapat hasil perbandingan yang ditunjukkan pada Tabel 7.

Tabel 7. Hasil pengujian dengan dan tanpa pra-pemrosesan NLP.

\begin{tabular}{ccc}
\hline $\begin{array}{c}\text { Hasil } \\
\text { Pengujian }\end{array}$ & $\begin{array}{c}\text { Tanpa Pra- } \\
\text { pemrosesan }\end{array}$ & $\begin{array}{c}\text { Dengan Pra- } \\
\text { pemrosesan }\end{array}$ \\
\hline Akurasi & $69,23 \%$ & $76,92 \%$ \\
\hline Presisi & $80,00 \%$ & $80,00 \%$ \\
\hline Recall & $64,52 \%$ & $74,07 \%$ \\
\hline
\end{tabular}

Hasil pengujian pada Tabel 7 menunjukkan bahwa klasifikasi melalui pra-pemrosesan tanpa pendekatan NLP menunjukkan hasil akurasi 69.23\% sedangkan klasifikasi melalui pra-pemrosesan dengan pendekatan NLP menunjukkan peningkatan hasil akurasi menjadi 76,92\%. Presisi dari kedua data menunjukkan hasil sama yaitu 80,00\%. Nilai recall data melalui pra-pemrosesan tanpa NLP menunjukkan hasil 64,52\% dan melalui pra-pemrosesan dengan NLP menunjukkan peningkatan menjadi 74,07\%. Secara keseluruhan hasil klasifikasi mengalami peningkatan pada data yang telah melalui tahap pra-pemrosesan 
menggunakan pendekatan NLP. Penerapan pra-pemrosesan dengan NLP memungkinkan mengubah kata tidak baku dan singkatan menjadi seragam, sehingga penerapan pembobotan kata dan penghitungan frekuensi kemunculan kata yang sudah seragam dengan TF-IDF menjadi lebih efektif.

Penelitian sebelumnya [30] menggunakan algoritma KNN dan TF-IDF dalam mengklasifikasi sentimen pada media sosial Twitter memperoleh akurasi 67,2\%. Sedangkan pada penelitian ini memperoleh akurasi lebih tinggi yaitu 76,92\%. Nilai akurasi yang lebih rendah pada penelitian sebelumnya disebabkan karena tidak menggunakan word normalizer sehingga penggunaan kata tidak baku dan kesalahan penulisan kata maupun singkatan pada kebiasaan pengguna Twitter tidak ditangani dengan baik. Penelitian lainnya [31] tentang Deep Sentiment Analysis pada angket penilaian terbuka menggunakan KNN menghasilkan presisi 59,4\%. Pada penelitian ini menghasilkan presisi $80 \%$, di mana sistem dapat memprediksi 40 ulasan dari 52 ulasan yang diuji.

\subsection{Frekuensi Kemunculan Kata}

Kata-kata yang mempunyai frekuensi kemunculan yang tinggi dalam ulasan dapat menggambarkan keadaan penerimaan pasar secara umum pada produk. Kata yang sering digunakan dalam memberikan ulasan di Shopee pada produk "hijab instan" ditunjukkan dengan wordcloud yang dibuat dengan aplikasi Wordart pada Gambar 4 dan Gambar 5.

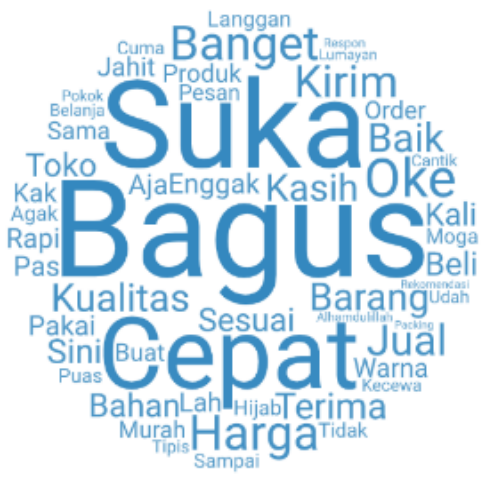

Gambar 4. Wordcloud kemunculan kata pada ulasan positif.

Pada ulasan dengan label positif, kata yang memiliki frekuensi kemunculan lebih dari 50 kali adalah kata "bagus" 123 kali, kata "suka" 99 kali, kata "cepat” 68 kali, kata "banget" 56 kali, kata "harga" 55 kali, dan kata "barang" 53 kali. Penggunaan kata "bagus", "barang”, "suka”, dan "banget" merujuk pada kualitas produk yang diterima yang sesuai harapan pembeli. Penggunaan kata "cepat" merujuk pada kecepatan pengiriman produk yang baik, sedangkan penggunaan kata "harga" merujuk pada penentuan harga yang baik untuk produk hijab instan dari sudut pandang pembeli.

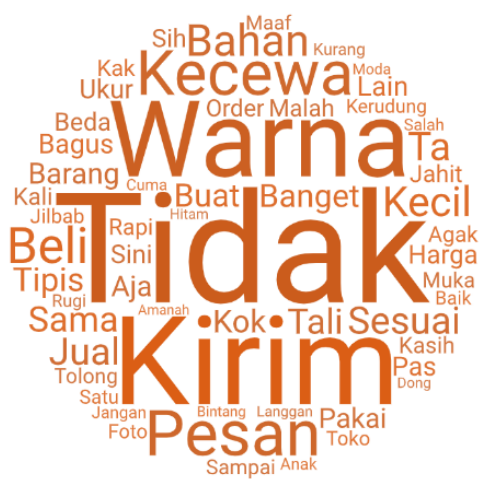

Gambar 5. Wordcloud kemunculan kata pada ulasan negatif.

Pada ulasan dengan label negatif, kata yang memiliki frekuensi kemunculan lebih dari 50 kali adalah kata "tidak" 168 kali, kata "warna" 67 kali, kata "kirim" 55 kali, kata "kecewa" 50 kali, dan kata "pesan" 55 kali. Kata "tidak" dan "kecewa" menunjukkan pembeli menerima keadaan yang tidak cocok dengan harapannya, seperti kata "tidak" yang diikuti dengan kata "warna" yang merujuk pada warna dari produk hijab instan yang diterima pembeli tidak sesuai. Kata "tidak" yang diikuti kata "kirim" dan "pesan" 
merujuk pada jumlah produk atau spesifikasi produk yang dikirim tidak sesuai dengan apa yang dipesan oleh pembeli.

Dari frekuensi kata yang muncul pada ulasan positif dan ulasan negatif, dapat menggambarkan keadaan pada segmentasi penjualan hijab instan di Shopee di mana sebagian pembeli merasa puas pada kualitas produk, kecepatan pengiriman produk dan harga produk. Sedangkan sebagian pembeli merasa tidak puas pada warna produk dan jumlah pengiriman produk yang tidak sesuai dengan yang dipesan oleh pembeli.

\section{Kesimpulan}

Ulasan produk pada marketplace Shopee dibutuhkan oleh calon pembeli untuk mencari informasi tentang kualitas produk yang akan dibeli, sekaligus sebagai masukan untuk penjual dalam meningkatkan kualitas produk dan pelayanan. Pemberian bintang pada ulasan tidak selalu dapat menggambarkan isi dari ulasan, hal ini dibuktikan adanya pemberian jumlah bintang yang tinggi, tetapi isi dari ulasannya bernilai negatif. Analisis sentimen pada isi ulasan produk dapat memberikan informasi yang lebih dalam tentang penilaian pembeli pada produk yang dijual di marketplace Shopee.

Penggunaan pendekatan NLP pada pra-pemrosesan data untuk meningkatkan akurasi klasifikasi sangat diperlukan. Fitur Word Normalizer berfungi untuk memperbaiki bahasa yang tidak baku dan singkatan yang digunakan dalam ulasan, seperti "tdk", "gak", "g", "tdak", "ga", dan "gk" yang dapat diseragamkan menjadi kata "tidak". Fitur Stemming dan Stopword removal juga dapat meningkatkan akurasi klasifikasi, terbukti dengan penerapan ketiga fitur tersebut, dapat menghasilkan nilai akurasi menjadi 76,92\%, presisi 80,00\%, dan recall 74,07\%, hasil ini lebih tinggi di bandingkan dengan klasifikasi yang tidak menggunakan fitur NLP yang hanya menghasilkan nilai akurasi sebesar 69,23\%, presisi 80,00\%, dan recall $64,52 \%$.

Penelitian ini menemukan bahwa kata-kata yang dominan pada ulasan positif adalah kata "bagus", "suka", "cepat", "banget", "harga", dan "barang" yang menunjukkan produk hijab instan mendapat ulasan positif dari pembeli dari segi kualitas barang, kecepatan pengiriman dan harga barang. Sedangkan kata-kata yang dominan pada ulasan negatif adalah "tidak", "warna", "kirim", "kecewa", dan "pesan" yang menunjukkan produk hijab instan mendapat ulasan negatif dari pembeli dari segi ketidaksesuaian warna serta jumlah atau spesifikasi barang yang dikirim dengan barang yang dipesan oleh pembeli.

Hasil penelitian ini dapat diterapkan untuk sistem analisis pemasaran dengan menggali informasi dari ulasan yang diberikan pembeli di marketplace, sehingga informasi yang didapat bisa digunakan sebagai masukan bagi penjual dalam meningkatkan produk dan pelayanannya. Informasi ini juga dapat digunakan oleh penjual lain untuk kegiatan analisis kompetitor. Dengan menganalisis kelemahan dan keunggulan dari produk dengan memanfaatkan informasi pada ulasan, memungkinkan penjual untuk dapat menghadirkan produk yang mampu menutupi kekurangan dan meningkatkan keunggulan produk dibanding kompetitor.

\section{Daftar Pustaka}

[1] A. K. Putra, R. D. Nyoto, and P. H. Sasty, "Rancang Bangun Aplikasi Marketplace Penyedia Jasa Les Private Di Kota Pontianak Berbasis Web,” J. Sist. dan Teknol. Inf., vol. 5, no. 1, pp. 22-25, 2017.

[2] IPrice, "Peta E - Commerce Indonesia," 2018. https://iprice.co.id/insights/mapofecommerce/ (accessed May 04, 2020).

[3] H. Wang and Y. Wang, "A Review of Online Product Reviews," J. Serv. Sci. Manag., vol. 13, no. 01, pp. 88-96, 2020, doi: 10.4236/jssm.2020.131006.

[4] A. Spink, B. J. Jansen, D. Wolfram, and T. Saracevic, "From E-sex to e-commerce: Web search changes," Computer (Long. Beach. Calif)., vol. 35, no. 3, pp. 107-109, 2002, doi: 10.1109/2.989940.

[5] J. Seth and H. Sidgwick, "Toward the Next Generation of Recommender Systems: A Survey of the State-of-the-Art and Possible Extensions," IEEE Trans. Knowl. Data Eng., vol. 17, no. 6, pp. 734749, 2005, doi: 10.2307/2176678.

[6] I. R. S. Servanda, R. K. S. Putri, and N. A. Ananda, "Peran Ulasan Produk dan Fot Produk yang Ditampilkan Penjual pada Marketplace Shopee terhadap Minat Beli Pria dan Wanita," J. Manaj. dan Bisnis, vol. 2, no. 2, pp. 69-79, 2019, doi: 10.37673/jmb.v2i2.526.

[7] M. Firdaus, F. Rizki, F. Gaus, and I. Susanto, "Analisis Sentimen Dan Topic Modelling Dalam Aplikasi Ruangguru," J-SAKTI (Jurnal Sains Komput. dan Inform., vol. 4, p. 66, Mar. 2020, doi: 10.30645/j-sakti.v4i1.188.

[8] K. S. Samith, "Sentiment Analysis System for Product Review: A Survey,” no. April, pp. 268-278, 2015, doi: 10.3850/978-981-09-5346-1_cse-571.

[9] B. Ahmed and A. Ghabayen, "Review Rating Prediction Framework Using Deep Learning," $J$. Ambient Intell. Humaniz. Comput., Mar. 2020, doi: 10.1007/s12652-020-01807-4. 
[10] M. Nurul, N. Soewarno, and I. Isnalita, "Pengaruh Jumlah Pengunjung, Ulasan Produk, Reputasi Toko Dan Status Gold Badge pada Penjualan Dalam Tokopedia," E-JA (e-Jurnal Akuntansi), vol. 28, no. 3, pp. 1855-1865, 2019, doi: 10.24843/EJA.2019.v28.i03.p14.

[11] A. A. Lutfi, A. E. Permanasari, and S. Fauziati, "Sentiment Analysis in the Sales Review of Indonesian Marketplace by Utilizing Support Vector Machine," J. Inf. Syst. Eng. Bus. Intell., vol. 4, no. 1, p. 57, 2018, doi: 10.20473/jisebi.4.1.57-64.

[12] Muljono, D. P. Artanti, A. Syukur, A. Prihandono, and D. R. I. M. Setiadi, “Analisis Sentimen Untuk Penilaian Pelayanan Situs Belanja Online Menggunakan Algoritma Naïve Bayes," in Konferensi Nasional Sistem Informasi 2018, 2018, pp. 8-9, [Online]. Available: http://jurnal.atmaluhur.ac.id/index.php/knsi2018/article/view/353.

[13] K. Norman, Z. Li, Y. T. Oh, G. Golwala, S. Sundaram, and J. Allebach, "Application of natural language processing to an online fashion marketplace," IS T Int. Symp. Electron. Imaging Sci. Technol., pp. 1-5, 2018, doi: 10.2352/ISSN.2470-1173.2018.10.IMAWM-444.

[14] E. Cambria, S. Poria, A. Gelbukh, and M. Thelwall, "Sentiment Analysis Is a Big Suitcase," IEEE Intell. Syst., vol. 32, pp. 74-80, Nov. 2017, doi: 10.1109/MIS.2017.4531228.

[15] M. T. Khan, M. Durrani, A. Ali, I. Inayat, S. Khalid, and K. H. Khan, "Sentiment analysis and the complex natural language," Complex Adapt. Syst. Model., vol. 4, no. 1, 2016, doi: 10.1186/s40294016-0016-9.

[16] G. Trends, "hijab instan, hijab persegi, hijab voal - Explore - Google Trends." https://rends.google.com/trends/explore?geo=ID\&q=hijab instan,hijab persegi,hijab voal (accessed Apr. 28, 2020).

[17] Shopee, "Harga Hijab Instan Terbaik." https://shopee.co.id/search?keyword=hijab instan\&page $=0 \&$ sortBy $=$ sales $($ accessed Apr. 28, 2020).

[18] A. Solichin, "MySql 5: Dari Pemula Hingga Mahir,” Univ. Budi Luhur, Jakarta, Jan. 2010.

[19] M. Mhatre, D. Phondekar, P. Kadam, A. Chawathe, and K. Ghag, "Dimensionality reduction for sentiment analysis using pre-processing techniques," in 2017 International Conference on Computing Methodologies and Communication (ICCMC), 2017, pp. 16-21, doi: 10.1109/ICCMC.2017.8282676.

[20] L. A. Mullen, K. Benoit, O. Keyes, D. Selivanov, and J. Arnold, "Fast, Consistent Tokenization of Natural Language Text," J. Open Source Softw., vol. 3, no. 23, p. 655, 2018, doi: 10.21105/joss.00655.

[21] B. P. Pande and H. S. Dhami, "Application of Natural Language Processing Tools in Stemming," Int. J. Comput. Appl., vol. 27, no. 6, pp. 14-19, 2011, doi: 10.5120/3302-4530.

[22] A. Prakash and U. Kumar, "International Journal of Computer Sciences and Engineering Open Access Authentication Protocols and Techniques: A Survey," no. March, 2019, doi: 10.26438/ijcse/v6i6.10141020.

[23] R. Melita, V. Amrizal, H. Suseno, and T. Dirjam, "Penerapan Metode Term Frequency Inverse Document Frequency (Tf-Idf) dan Cosine Similarity pada Sistem Temu Kembali Informasi untuk Mengetahui Syarah Hadits Berbasis Web (Studi Kasus: Hadits Shahih Bukhari-Muslim)," J. Tek. Inform., vol. 11, no. 2, pp. 149-164, Nov. 2018, doi: 10.15408/jti.v11i2.8623.

[24] V. Jahjah, R. Khoury, and L. Lamontagne, Word Normalization Using Phonetic Signatures. 2016.

[25] J. Asian, H. E. Williams, and S. M. M. Tahaghoghi, "Stemming Indonesian," Conf. Res. Pract. Inf. Technol. Ser., vol. 38, no. January, pp. 307-314, 2005, doi: 10.1145/1316457.1316459.

[26] M. Khader, A. Awajan, and G. Al-Naymat, "The Effects of Natural Language Processing on Big Data Analysis: Sentiment Analysis Case Study," in 2018 International Arab Conference on Information Technology (ACIT), 2018, pp. 1-7, doi: 10.1109/ACIT.2018.8672697.

[27] D. Astuti and M. Lutfi, "Analisis Pengaruh Kualitas Pelayanan Dan Kepuasan Pelanggan Terhadap Loyalitas Pelanggan," J. Ekobis Ekon. Bisnis Manaj., vol. 9, pp. 132-144, Mar. 2020, doi: 10.37932/j.e.v9i2.64.

[28] A. Tripathy, A. Agrawal, and S. K. Rath, "Classification of sentiment reviews using n-gram machine learning approach," Expert Syst. Appl., vol. 57, pp. 117-126, 2016, doi: https://doi.org/10.1016/j.eswa.2016.03.028.

[29] A. Tharwat, "Classification Assessment Methods," Appl. Comput. Informatics, no. January, 2018, doi: 10.1016/j.aci.2018.08.003.

[30] A. Deviyanto and M. D. R. Wahyudi, "Penerapan Analisis Sentimen Pada Pengguna Twitter Menggunakan Metode K-Nearest Neighbor,” JISKA (Jurnal Inform. Sunan Kalijaga), vol. 3, no. 1, pp. 1-13, 2018, doi: 10.14421/jiska.2018.31-01.

[31] J. Riany, M. Fajar, and M. P. Lukman, "Penerapan Deep Sentiment Analysis pada Angket Penilaian Terbuka Menggunakan K-Nearest Neighbor," Sisfo, vol. 06, no. 01, pp. 147-156, 2016, doi: 10.24089/j.sisfo.2016.09.011. 